\title{
Discussion on How Personal Factors Can Affect English Learning Motivation of Senior High School Students in China
}

\author{
Jinxin Xue $\mathrm{e}^{1, *}$ \\ ${ }^{1}$ Graduate School of Faculty of Arts, Hong Kong Baptist University, Hong Kong, China \\ *Corresponding author. Email: 20445482@life.hkbu.edu.hk
}

\begin{abstract}
English learning performance can be highly influenced by students' learning motivation, which is a kind of positive psychological state making students keep learning. The learning of English in senior high school in China mainland is a long-term process. Students' performance of this schooling level can vary, and their personal factors are one of those responsible for the variation. There are three personal factors examined in this research, including self-efficacy, emotion, and learning strategy. With the help of previous studies, this research is trying to find out the correlation between personal factors and learning motivation of English to offer feasible advice to English teachers to help senior high students maintain their learning motivation to better performance finally.
\end{abstract}

Keywords: Senior high school students, China, English performance, learning motivation, self-efficacy, emotion, learning strategy.

\section{INTRODUCTION}

A second language is offered widely by the curriculum in senior high schools in China mainland, and English is the most popular one. Despite this popularity, senior high school students' performance of English can vary or even polarize. A few students can learn English with remarkable grades, while most students may struggle to get a pass for this foreign language, and some even have quitted completely.

Learning motivation may be the most elementary factor that can influence it when it comes to learning performance. The factors that can affect the performance of English in senior high school are abundant, and personal factor is one of them. This research has included three potential kinds of it: self-efficacy, emotion, and learning strategy.

Self-efficacy is highly connected with students' learning performance, and recently the sense of selfefficacy is commonly lower among most senior high school students. Thereby, their academic performance is negatively influenced, so is their psychological health [1]. Positive emotions can make senior high school students target-oriented, objective, and optimistic; however, negative emotions could cause them unenthusiasm, disturbance, and poor learning performance. These negative effects seem to be more apparent for the subject of English [2]. Learning strategies are dominantly, positively correlated with English performance [3]. English learning strategy is one of the determining factors of academic performance of English [4].

With careful reference to the previous literature, the research is trying to find out whether the personal factor is correlated with the English learning motivation of senior high school students; moreover, how the personal factor can affect the English learning motivation were also examined.

It is of theoretical importance to study the questions. First, this can expand the previous literature by examining the correlation between the personal factors and English learning motivation. In addition, the research also has practical implications for English teachers in senior high school, enriching their knowledge about how to intervene in helping students maintain their learning motivation. With stable or soaring learning motivation, students' learning performance can be positively predictable. 


\section{METHOD}

With the help of the database of HKBU library, the author searched more than eighty related essays and papers with the keywords (senior high school students, China, learning motivation, English learning, English performance, self-efficacy, emotion, and learning strategy). Inevitably, a range of essays might not be very suitable for this topic for some reasons, so some standards were used to help to decide whether one essay is closely related or not, including target subject, contexts, and effectiveness etc. The target subject of this research is the senior high school students in Chinese mainland; however, those papers whose subjects are not within this limit may not be suitable for this research, for example, subjects in primary school or university. If an essay was issued in a period over twenty years from now, its social and educational contexts might have been too different from those nowadays, so this essay might not be applicable. Additionally, one essay which is concerned with the learning of Spanish rather than English, its effectiveness might not be strong enough to solve the recent problem. With this careful filtration, twenty-five papers which are closely related were left for reference.

\section{INFLUENTIAL FACTORS}

\subsection{Self-efficacy}

Self-efficacy is the extent to which individuals believe in their ability to successfully execute a task [5], and self-efficacy belief among all the beliefs seems to have the most influential power in human agency [6]. Self-efficacy is also key to academics, more precisely, students' learning performance; namely, both are positively correlated.

Students who believe in themselves always may not frown upon practicing until they can make it, and learning a second language really requires learners to keep trying and practicing. With a higher level of selfefficacy, students can perform better in learning to gain higher grades for the subject of English. Joo has found that self-efficacy is positively correlated to students' grades, performance, scores on exams, and quizzes, etc. [7]. In addition, Jabbarifar concluded that self-efficacy helps determine how much effort people will make and how long they persist; the higher the sense of efficacy, the greater would be the effort, expenditure, and persistence [8].

The grades that students can get are closely connected to the efforts that they have made. Ci stated that learning motivation is highly connected with grades [9]. It is found that self-efficacy developed in domainspecific learning helps students to develop abundant abilities, such as cognitive strategies, critical thinking, teamwork communication, and so on [10]. Keeping trying is positively relevant to academic performance. With more efforts and higher abilities, students can feel surer about themselves while completing their tasks in the learning of English, and they are more likely to acquire better grades with such self-efficacy

\subsection{Emotion}

Emotion is important to learning motivation. Positive emotions can encourage students to keep trying and never give up; negative emotions, on the other hand, can sometimes undermine their motivation to learn and lead to the poor academic performance of learning English finally. Both positive and negative emotions can influence students' learning motivation [11].

In addition, negative emotions (e.g., anxiety and lassitude) are primarily responsible for the gradual decline of students' normal thinking process [12]. Senior high school students are still at a young age, and they might be immature psychologically, so their emotions might be susceptible to fluctuation. Due to age, experiences, and mentality limitations, senior high school students are in a special phase in their lives where their hearts can rule their brains easily. This is also a phase in which emotions consist of one of the influential factors for their academic performance [2].

Moreover, negative emotions can be destructive to English learning motivation. Research conducted by Xv concluded that the sense of lassitude for English learning among senior high school students is more striking than that for other subjects. Lassitude can make students tired of learning English and finally quit completely [13]. Anxiety is a kind of negative emotion, which could impact a student's academic performance, too. The lower their English academic performance, the more foreign language classroom anxiety students had in communication apprehension, test anxiety, or fear of negative evaluation [14].

\subsection{Learning Strategy}

Learning strategy is one of the influential personal factors that can contribute to a better grade of learning. According to Chamot, learning strategies are techniques, approaches, or deliberate actions that students take to facilitate the learning and recall of both linguistic and content area information (p. 71) [15].

A study by Fang concluded that using learning strategies to facilitate English learning is exactly crucial to promote grades [16]. Zhang stated that improving students' learning efficiency is one of the most urgent problems that educators need to address, and a potential 
solution is to widen the study and the implementation of learning strategies to help students find the one that is proper for themselves [17]. According to a research conducted by $\mathrm{Wu}$, whether students apply strategies to learning English is positively correlated to the level of performance of English among senior high students. Its result showed that students with excellent English performances are accomplished at learning English strategically [18].

In general, more proficient learners usually use a wide range of strategies than less proficient learners [19].

\section{IMPLICATIONS FOR TEACHING}

Knowing the importance of the three personal influential factors to English learning motivation and performance, English teachers could help senior high students with diverse methods accordingly.

Regarding self-efficacy, English teachers could make students experience more sense of achievement, which can originate from success. A successful learning experience should be the most solid base on which selfefficacy can be built. It can also make students believe in their own abilities to address difficulties [20]. Teachers may optimize teaching and evaluation methods to meet students' needs for success to maintain their learning motivation. Students usually care about teachers' evaluations, and those negative ones could weaken the degree that students believe in themselves [21].

Sense of achievement can also help to deal with negative emotions. According to Zhou, most senior high school students have expectations of learning English well; however, if their learning performance cannot match their long-term efforts, they may get discouragement, inferiority, and anxiety [21]. English teachers can find solutions to let students experience the positive correlation between their efforts and performance to address these negative emotions. With the incentive of promoting grades, students can become more interested in learning English, which can further facilitate their learning [22].

As mentioned above, those who got good grades in English are accomplished at learning strategically. Students need to find suitable learning strategies for themselves, which cannot go smoothly without help from English teachers. According to a study by Ma, students tend to choose the learning strategies compatible with their sensory learning styles, which normally include hearing, seeing, experiencing, and hand-operating [23]. Teachers can guide students to know the mechanism that they learn knowledge and to find suitable learning strategies.
Although the three personal factors can influence students' learning motivation and performance independently, teachers can combine them to help students maintain learning motivation when necessary. Suppose English teachers better understand the relationship between self-efficacy, emotion, and students' abilities. In that case, they can design more efficient teaching strategies, which could help students handle the problems they encounter during a foreign language class and facilitate their learning experience [24]. According to a survey by Chen, emotional state is an essential, influential factor of self-efficacy: positive emotions could cause higher self-efficacy [20]. Oxford also defined learning strategies are a set of actions taken by learners to learn a second language independently and happily [25]. Thus, English teachers can also use the interaction among the three personal factors of students to help them comprehensively maintain learning motivation.

\section{CONCLUSION}

This research studies the correlation between the personal factors and the English learning motivation of Chinese senior high school students. The personal factors include self-efficacy, emotion, and learning strategy. As shown in the research, the personal factors and the English learning motivation are positively correlated with each other.

More precisely, self-efficacy can determine how much effort a student will make and how long he or she will persist. The effort and the persistence may decide the grade that they can get from learning English. Better grade can be helpful for maintaining their learning motivation. In addition, emotions, positive and negative, can also be responsible for the up-and-down of English learning motivation of senior high school students. Negative emotions, for example, lassitude and anxiety, can make students tire of learning English and even quit completely. And learning English strategically may play an important role in maintaining students' learning motivation and performance. Proficient learners can apply a range of learning strategies than less proficient learners.

The research also has practical implications for English teachers to maintain students' learning motivation. Interventions for this purpose can be used to make students experience more sense of achievement, which can be helpful for students to retain self-efficacy and tackle negative emotions. Furthermore, English teachers could help senior high school students to find the learning strategies that are compatible with themselves.

Finally, in this research, only three personal factors have been estimated. However, other influential factors on students' grades and learning motivation are still not included in this research, such as school, curriculum, 
teachers, and interpersonal relationships between students, etc. As for these, more researches are needed to find out how those factors could affect students' grades of English, how they connect with each other, and what kind of influence that impose on students' English learning motivation.

\section{REFERENCES}

[1] X.Y. Yv, (2012). Liyong ziwo xiaoneng gan tigao gaozhong yingyu ketang xiaolv [Employing selfefficacy to promote the efficiency of senior high school English classes], Xueyuan Jiaoyu, 2012(4), 68 .

[2] N. W. Li, (2014). Qiantan qingxv ganshou dui gaozhong Yingyv jiaoxue de yingxiang [Discussion on the influence that emotional feelings impose on the teaching and the learning of English in senior high school], Xin kecheng daoxue (Qi nianji shangxun), 2014(21), 59.

[3] J. H. Zhu, (2010). Gaozhongsheng Yingyu xuexi celve yu xuexi chengji guanxi de shizheng fenxi [Analysis of the evidence of correlation between English learning strategy and academic grades of senior high school students], Jiaoxue yu guanli: lilun ban , 2010 (3), 49- 50. httpsdoi.org10.3969j.issn.1004-5872.2010.03.023

[4] Q.F. Wen, (1996). Yingyu xuexi celve lun [Theory about English learning strategy], Shanghai Foreign Language Education Press

[5] A. Bandura, (1997). The exercise of control. Freeman.

[6] A. Bandura, (1986). Social foundations of thought and action: A social cognitive theory. Prentiee-Hall.

[7] Y. Joo, M.Bong, \& H. Choi (2000). Self-efficacy for self-regulated learning, academic self-efficacy, and internet self-efficacy in web-based instruction. Educational Technology Research and Development, 48(2), 5-17. https://doi.org/10.1007/BF02313398

[8] T. Jabbarifar (2011). The importance of selfefficacy and foreign language learning in the 21st Century, Journal of International Education Research, 7(4), 117-126. https://doi.org/10.19030/jier.v7i4.6196

[9] Z. G. Ci (2013). Ruhe peiyang he jifa gaozhongsheng de Yingyv xuexi dongji [How to nurture and stimulate English learning motivation of senior high school students, Kaoshi zhoukan, 2013(62), 92-93.

[10] S. Tzeng \& H. Nieh (2015). How self-concept, selfefficacy and self-evaluation relate to relate to achievement outcomes: New technology-based learning models for science and technology universities students, 2015 International Conference on Interactive Collaborative Learning (ICL), 863870. https://doi.org/10.1109/ICL.2015.7318141

[11] R. Pekrun, T. Goetz, W. Titz, \& R. P. Perry, (2002). Academic emotions in students' self- regulated learning and achievement: A program of qualitative and quantitative research, Educational Psychologist, 37(2), 91-105. https://doi.org/10.1207/S15326985EP3702_4

[12] E.Jang, B.Park, S.Kim, \& J. Sohn (2012). Emotion classification based on physiological signal induced by negative emotions: Discrimination of negative emotions by machine learning algorithm, Proceedings of 2012 9th IEEE International Conference on Networking, Sensing and Control, 283-288. https://doi.org/10.1109/ICNSC.2012.6204931

[13] X. B. Xv (2014). Gaozhongsheng xuexi juandai qingkuang ji duice [Situation and countermeasure of lassitude of English learning of senior high school students], Shandong shifan daxue waiguoyu xueyuan bao: jichu Yinhyu jiaoyu, 2014, 16(1), 1116.

[14] J.-R.Wang, L. Caviness, \& La Sierra University. (2011). Foreign language classroom anxiety and English academic performance among medical university students in Taiwan

[15] A. Chamot (1987). The learning strategies of ESL students'. In A. Wenden and J. Rubin (Eds.), Learner strategy in language learning (pp. 71-83). Englewood Cliffs, N.J.: Prentice Hall

[16] Y. G. Fang (2010). Gaozhongsheng Yingyu xuexi celve yv chengji de xiangguan yanjiu [A research on English learning strategy of senior high school students and academic record], Xiandai jiaoyv kexue (pujiao yanjiu), 2010 (1), 80-82.

[17] J. Zhang (2015). Gaozhongsheng Yingyv xuexi celve yu xinli ziben de guanxi [The correlation between English learning strategy of senior high school students and psychological capital] Shandong shifan daxue waiguoyv xueyuan xuebao: jichu jiaoyv, 17(5), 25-31.

[18] J. Y. Wu (2011). Gaozhongsheng Yingyu xuexi celve ji xuexi chengji diaocha fenxi [Survey and analysis on senior high school students' English learning strategy and academic record], Xin kecheng yanjiu: jichu jiaoyv, 2011(12), 74-76

[19] J. M. Magogwe \& R. Oliver (2007). The relationship between language learning strategies, proficiency, 
age and self-efficacy beliefs: A study of language learners in Botswana. System, 35(3), 338-352.

[20] W. L. Chen (2015). Gaozhongsheng xuexi dongji, ziwo xiaoneng gan ji xuesheng ganzhi de jiaoshi zhichi yv Yingyv chengji de guanxi yanjiu [A Study on the Relationship between English Performance and Senior High School Students' Learning Motivation, Self-efficacy, and Teachers' Support Sensible to Students], Longdong xueyuan xue bao, 26 (3), 107-109

[21] Y. Y. Zhou (2017). Gaozhongsheng Yingyv xuexi jiaolv zhuangtai ji duice tantao [Discussion on the State of Learning Anxiety of Senior High School Students and Possible Solutions], Xiaoyuan Yingyv, 10, 117-117.

[22] G. Y. Yue (2013). Zhongxuesheng Yingyv xuexi dongji yanjiu [A Study on the English Learning Motivation of High School Students], Kaoshi zhoukan, 29, 91-92.

[23] J. Y. Ma (2017). Gaozhongsheng Yingyv xuexi celue yu xuexi fengge pianhao de xiangguanxing yanjiu [A Study on the Relevance between English Learning Strategies and Learning Style Preferences of Senior High School Students], Kecheng Jiaoyv yanjiu, 7, 92-93.

[24] Passiatore, Ylenia, Pirchio, Sabine, Oliva, Clorinda, Panno, Angelo, \& Carrus, Giuseppe. (2019). Selfefficacy and anxiety in learning English as a Foreign language Singing in class helps speaking performance. Journal of Educational, Cultural, and Psychological Studies, 2019 (20), 121-138. http://doi.org/10.7358/ecps-2019-020-passi

[25] R. Oxford, Language Learning Strategies: what every teacher should know [M]. New York: Newbury House, 1990. 